\title{
El asedio a la cristiandad. Intelectuales católicos y sociedad (1950-1965) ${ }^{1}$
}

José A. Zanca

Universidad de San Andrés/CONICET, Argentina

Desde el atardecer del papado de Pío XII a la finalización del Concilio Vaticano II, el catolicismo vivió una autentica revolución interna. El trabajo propone analizar la trayectoria de los discursos de la intelectualidad católica argentina en las décadas del cincuenta y sesenta, y las condiciones que hicieron posible ese cambio. El período conciliar fue capaz de modificar el sistema de relaciones al interior del catolicismo y las formas de sanción y legitimidad de los discursos en el campo: lo decible y no decible sufrió una transformación radical. Temas como el rol de los laicos, el pluralismo, el diálogo ecuménico, la relación Iglesia - Estado, etc., formaron las coordenadas de ese intenso debate.

Palabras ClaVE: Intelectuales católicos, Iglesia argentina, Concilio Vaticano II, Pío XII, Historia de la Iglesia.

From the decline of Pius XII's papacy to the end of the Vatican Council II, Catholicism faced an actual internal revolution. This paper seeks to analyse the development of discourse in Argentinian catholic thinkers in the 1950s and 1960s; and the conditions under which this change has been possible. The conciliary period was capable of transforming the inner relational system in catholicism and modifying the ways of sanction and legitimacy of discourse in the field: what can and what cannot be said underwent a radical transformation. Issues such as the role of laymen, pluralism, ecumenical dialogue, the relationship Church-State, etc., set up the coordinates of this intense debate.

KeYwords: Catholics thinkers, Argentinian Church, Vatican Council II, Pius XII, Church History.

El presente ensayo intenta dar cuenta, en forma sintética, de las principales transformaciones operadas en el universo cultural católico en las décadas del ' 50 y '60. En primer lugar se vislumbra el surgimiento de una generación de intelectuales que ve la luz pública después de 1955, que se

1 Una versión de este texto fue presentada en 2004 en el encuentro "Católicos en el siglo. Política y cultura", organizado por la Universidad Nacional de Quilmes de la República Argentina. Agradezco los comentarios que oportunamente me formulara el profesor Luis Alberto Romero. 
adscribe al programa del humanismo cristiano y es portadora de una mirada distinta a la de sus predecesores nacionalistas e integristas de la década del treinta y cuarenta. Asimismo, las relaciones de autoridad dentro del campo se verán trastocadas por el surgimiento de una esfera crítica dentro del catolicismo, que obtendrá carta de ciudadanía con el Concilio Vaticano II. Se han tomado como balizas temporales la emisión de la encíclica Humani Generis en 1950, en la que Pío XII advertía sobre las desviaciones del pensamiento católico, y la aprobación de la constitución pastoral sobre la Iglesia y el mundo moderno Gaudium et Spes, en la clausura del Concilio Vaticano II, que hizo propias muchas de la ideas condenadas quince años antes.

\section{La generación del '50}

Los intelectuales católicos formaban parte de un grupo marginal en una década de confrontación de modelos ideológicos irreconciliables. Desde el derrocamiento del peronismo, la intelectualidad no confesional los acusó por su acción u omisión frente al régimen depuesto. Sin embargo, la ruptura se había producido años atrás. La disputa en torno a la guerra civil española partió aguas; e incluso entre los mismos católicos la herida nunca terminó de sanar. Durante los años del peronismo, la tibieza de la jerarquía eclesiástica hacia el poder refrendó las teorías de la izquierda sobre la connivencia entre los sectores totalitarios y reaccionarios. A partir de 1956, el conflicto universitario involucró en forma polémica a los intelectuales católicos y al resto del universo cultural argentino (de raíces profundamente laicistas), demostrando que la convivencia había sido un producto circunstancial del enfrentamiento con el peronismo. Luego de una corta primavera durante el año '55, los católicos volvieron a distanciarse del resto de los intelectuales.

Pero tal vez esta situación no fuera la excepción sino la regla, los intelectuales católicos habían sido protagonistas de la escena pública en las décadas del ' 30 y del ' 40 , vaciando en el molde del nacionalismo la frustración que arrastraban desde mediados del siglo XIX. Luego de dos décadas en las que concentraron parte de la atención pública, en 1955 estaban de nuevo en el punto de partida. Solos, enajenados de una cultura nacional cada vez más laica, más anticlerical y politizada, parecían atados a su pasado. Aunque no podían desconocer esa realidad, en algún punto parecía no 
importarles, los más belicosos buscaban en el otro los defectos de tal estado de cosas. Según Mauricio Pérez Catán, los intelectuales argentinos criticaban a los católicos porque en definitiva eran "sectarios, y como tales, más o menos totalitarios, que aspiran a hacer un 'peronismo al revés', como lo han demostrado con su demagogia e inquisición, no siempre bien disimulada". ${ }^{2}$

Gustavo Martínez Zuviría lamentaba que, después de 1958, la marginación de los intelectuales católicos se hubiese convertido en indiferencia. "Dice el señor 'si el mundo os aborrece, sabed que primero me aborreció a mí [...] y el pobre intelectual contesta: Si señor. Pero lo malo es que nadie me persigue ¡Ojalá me persiguieran! Porque harían ruido a mi alrededor y me harían conocer. El silencio es la mayor arma de nuestros enemigos, que son los vuestros Señor". 3

Asumir ese lugar marginal no siempre implicó establecer lazos con el mundo moderno. La cristiandad como sueño de perfección y pureza les daba a los católicos un conjunto de seguridades, refrendadas en ámbitos de sociabilidad que cimentaban un verdadero sistema de obligaciones compartidas. ¿Qué había 'afuera', que realmente valiera la pena? Martínez Zuviría exorcizaba cualquier intento de borrar las fronteras entre uno y otro mundo. "Los católicos" denunciaba "aceptan muchas veces con demasiada generosidad, las famas y las obras del campo contrario". De esa complacencia con la modernidad, de ese conformismo con el mundo "anticatólico", nacía el relajamiento que le hacía temer a Zuviría que al joven intelectual católico "a la corta o a la larga pueden nacerle tentaciones de cambiar, de pasarse a la otra trinchera". ${ }^{4}$

Pero esos jóvenes ya existían. Habían formado una nueva conciencia bajo la universidad opresiva del peronismo, preguntándose si ésa era la revolución nacional que predicaban sus mayores. Leyeron a los clásicos del catolicismo de los años '30; conocieron a Maritain, a Bloy, a Berdiaeff y a Chesterton, pero también a los "sospechosos": Folliet, Guitton, Teilhard de Chardin y Mounier. Tomaron contacto con ellos en grupos de estudio reducidos, de la mano de religiosos carismáticos como Moledo, Franceschi, Etcheverry Boneo y también Meinvielle. Conocieron a los

2 Pérez Catán, M.: "Un totalitarismo que no cuenta para ciertos intelectuales argentinos", Estudios, 479, octubre de 1956, pág. 25.

3 Wast, H.: "El triste destino del intelectual católico", Estudios, 500, diciembre de 1958, pág. 763.

4 Ibídem, pág. 766. 
escritores católicos de la postguerra europea, y se enamoraron de la imagen de un catolicismo más íntimo y menos belicoso, más terrenal y menos triunfante. Esa nueva generación, que algunos llamaron "del cincuenta", no conoció la seguridad de sus mayores. Los católicos de la entreguerra habían gozado de un conjunto de convicciones sobre las que se erigieron como cruzados. Sabían que este mundo era irreconciliable con su imagen de Cristo y no admitieron transacciones, mientras se desplazaban en un medio fragmentado por ideas absolutas y opuestas. Los jóvenes del '50 también crecieron en una sociedad dividida, pero con el peronismo, el clima de la postguerra y las vísperas del Concilio, su pesimismo se trastocó en confianza, y creyeron poder establecer un diálogo con la modernidad. Adoptaron como programa el humanismo cristiano, una síntesis de sus aspiraciones de renovación. Sus nombres, Carlos Floria, Ludovico Ivanissevich Machado, José Luis de Imaz, Jorge Mejía, Emilio Mignone, Néstor Auza, Guido Di Tella, Horacio Peña, Antonio Donini, Rafael Braun, Justino O’Farrel, Alberto Sily, José E. Miguens — por sólo nombrar a algunos - poblaron las páginas de revistas de larga tradición en el catolicismo argentino como Criterio y Estudios. Para Martínez Zuviría, sólo "deleitaban al enemigo, que tiene singular predilección por los católicos 'discretos" ". 5

Esos jóvenes rechazaron el nacionalismo exasperado de la generación que los precedió. Les interesaba la política tanto como la introspección de su fe, pero las consideraron esferas autónomas. Dudaron de que la rigidez moral de la Iglesia fuera el único valor que la religión pudiera brindarle a la sociedad. Comenzaron por criticar películas y libros desde una perspectiva neutral, separando lo artístico de lo religioso. La Dolce vita podía ser condenada por la Acción Católica por inmoral, pero eso no impedía que recibiera los elogios de Jaime Potenze en Criterio. ${ }^{6}$ Las ciencias sociales sirvieron de vehículo para su cambio de perspectiva. Los intelectuales católicos de los ' 30 y ' 40 fueron en su mayoría religiosos, filósofos y abogados. Los jóvenes del '50 se convirtieron en sociólogos, cientificistas políticos, economistas e historiadores, y les tocó participar en la modernización de cada una de sus disciplinas. Tomaron distancia de sus propias convicciones y pudieron autointerpretarse desde una perspectiva diferente

5 Ibídem, pág. 765.

6 Ver la polémica entre Criterio y Estudios en la que Potenze defendía su derecho a juzgar el arte con autonomía de las apreciaciones morales en Criterio, 1215, 8 de julio de 1954; 1218, 26 de agosto de 1954 y Estudios, 467, abril- mayo de 1954; 468, junio-julio de 1954. 
a la de sus mayores, obtuvieron becas y viajaron, algunos conocieron universidades católicas europeas, que desde la postguerra hablaban un nuevo lenguaje.

Pero la nueva generación no cometió un parricidio. Las obligaciones sociales eran una atadura muy fuerte dentro del catolicismo. Los jóvenes del '50 simplemente dejaron atrás a la generación que les precedió, sin sistematizar una crítica que sirviera para una ruptura formal. La transición se suavizó por la existencia de intelectuales como Franceschi, que compartían ideas de los dos mundos. Su muerte en 1957 lo libró de un tiempo de enfrentamientos en el seno de la Iglesia donde, obligado a definiciones, no había podido mantener su tono conciliador. Su postura frente a la democracia había sido siempre ambigua, su recelo hacia el liberalismo era parte de la doctrina que había sostenido su pensamiento. ${ }^{7}$ Pero eso no le impedía criticar a quienes en los años treinta habían despreciado a las instituciones que garantizaban la libertad. Los escritos de sus últimos años, después de la caída del peronismo, se concentraron en aquellos temas que afectaban a la conciencia común de los católicos, y que luego serían recogidos por el Concilio Vaticano II: la cuestión social, la relación con el mundo moderno, la reconciliación con otros cultos, el distanciamiento del Estado...

Así como esa nueva generación no rompió con sus padres intelectuales, tampoco se reconcilió con el resto del mundo cultural. El conflicto universitario de 1958 por la autorización del funcionamiento de casas de altos estudios privadas, separó más y más las trincheras. Los católicos de la nueva generación quedaron atrapados entre la reivindicación de un pasado al que se sentían atados pero sin conformidad, y una nueva intelectualidad de izquierda que les exigían renuncias y rupturas que, por la conformación propia del campo y su relación con la jerarquía eclesiástica, ellos no podían aceptar. En otras condiciones, el paralelo cultural de estos jóvenes

7 Beatriz Sarlo describió la duda que enfrentaba el catolicismo social: “¿cuáles son las grandes líneas de organización de una democracia que evite los límites que a la justicia social pone el liberalismo, con su despliegue conflictivo de los intereses individuales, y el totalitarismo, con su intervención incontrolable tanto en la esfera privada como su absorción por el estado en los órganos de la comunidad?" en Sarlo, B.: La batalla de las ideas, Ariel, Buenos Aires, 2001, pág. 47. El pensamiento de Franceschi vivió en ese dilema hasta sus últimos días. Una editorial de 1957 todavía defendía el régimen autoritario de Oliveira Salazar en Portugal por sus éxitos económicos: "Es el modelo de austeridad personal y de la austeridad gubernativa. No ha pretendido conquistar al pueblo con discursos sino con hechos, no ha hablado de derechos sino de deberes, ha mostrado que únicamente el camino de la privación era el que permitiría reconstruir el mañana haciéndolo digno del pasado" en Franceschi, G.: "Austeridad", Criterio, 1281, 11 de abril de 1957, pág. 213. 
hubiera sido la generación de Contorno. ${ }^{8}$ Sin embargo, no existió un verdadero diálogo entre ambas.

A los católicos les agradaba la reivindicación que hacían los contornistas de figuras como Arlt, Quiroga o Cambaceres, tal vez por un desprecio común hacia el liberalismo de las letras argentinas. Sin embargo, el existencialismo y el izquierdismo anticlerical del grupo marcaron una frontera infranqueable: Un Dios cotidiano, de Viñas, donde se relataban episodios de la vida de un cura en la Argentina de fines de los treinta, fue rechazado con vehemencia por los críticos de Estudios y Criterio. Le reprocharon a Viñas "hablar de lo que no siente", y Gustavo Ferrari de Criterio sostuvo que el autor fracasó porque "el tema se le resbala de las manos, nunca está del todo a su alcance". ${ }^{9}$ Héctor Ferreiros, de Estudios, disparó contra el libro y sostuvo que en él "muchas ideas no abundan". ${ }^{10}$ Sin embargo, y a pesar de la dureza de las críticas, no había en los argumentos un fundamento clerical contra la obra. Lo que rechazaban de Un Dios cotidiano era la caricaturización de los problemas que ellos enfrentaban a diario: la forma de experimentar la fe, la presencia de Cristo en sus vidas, la relación con el mundo moderno y con la jerarquía de la Iglesia. A fines de los '50, los católicos querían dejar de ser la viñeta que el resto de los intelectuales hacía de ellos: un grupo cerrado e intolerante, tradicionalista y timorato; estaban cambiando y querían que el mundo lo supiera. Aunque no buscaban agradar, como los acusaba Martínez Zuviría, creían que era posible reintegrarse en el campo intelectual, diferenciándose de la intolerancia de sus predecesores. A pesar de las buenas intenciones, sus lazos de responsabilidad con el resto de los católicos — que pesaban de distinta manera en cada grupo de intelectuales - cercenaron la posibilidad de ese diálogo. Su ruptura incompleta con la generación de los nacionalistas los hacía deudores de un panteón al que, por más que criticaban, se sentían solidariamente unidos. Sin ir más lejos, la polémica figura de Martínez

8 En un artículo de 1958, Hector Ferreiros señalaba en referencia al grupo Contorno: "sus tópicos son anti-imperialistas, de lucha de clases, laicistas... en fin, un esquema marxista pero nacional y que últimamente cumpliendo con la predicción de José Chiaramonte: 'si no se inclinan a un socialismo científico...llegaran al borde de eso que es el saldo negativo de la Reforma, el aprismo...”. En forma paralela a Contorno, Ferreiros ubicaba al grupo de católicos de la revista Ciudad, dirigida por Carlos Manuel Muñiz, e integrada por Ezequiel Lezama, Ludovico Ivanissevich Machado, Eduardo Dessein, Magdalena Harriague, Eugenio Guasta y Rafael Squirru entre otros. Ver Ferreiros, H.: "Denevi - Viñas y nuestro contorno literario de hoy", Estudios, 493, mayo de 1958, págs. 250-252.

9 Ferrari, G.: "Un dios cotidiano, un Dios ausente", Criterio, 1305, 8 de abril de 1958, pág. 250.

10 Ferreiros: "Un dios...", pág. 251. 
Zuviría colocaba a muchos frente a una disyuntiva de hierro, negarlo implicaba arriesgarse a diluir su propia identidad, abrogar de las credenciales que le permitirían mostrar una producción en el terreno de la ideas. Asumirlo como propio era reconocer todo el lastre de su figura, su antisemitismo, la colaboración de los católicos con los gobiernos autoritarios; es decir, una síntesis de todo lo que rechazaban.

Tal vez ese temor a romper definitivamente con sus predecesores diluyó la presencia de la generación del '50. Los tradicionalistas católicos estaban amparados por la jerarquía, y en definitiva era la línea que Pío XII utilizaba para contener los embates de la nueva teología desde el fin de la Segunda Guerra. Sólo después del Concilio las diferencias dentro del catolicismo se pudieron mostrar legítimamente; pero serían otros jóvenes, adscriptos al tercermundismo, los que harían patente la ruptura.

A pesar de ese corte incompleto, a través de sus palabras es fácil apreciar la búsqueda de un perfil propio. Los jóvenes del ' 50 crecieron de golpe y se consideraban con derecho a reclamar cambios en el estilo del catolicismo. "Es paradojal", sostenía Carlos Floria en 1958, "que la necesidad de tener sentido común, tacto, ha sido más comprendida por los jóvenes de 35 años para abajo que por los más maduros. Creo que ello ocurre porque los cambios han sido tan febriles en estos 12 años que hemos recorrido uno 60 años de historia mundial [...] Los jóvenes nos hemos dado cuenta porque no temimos a la muerte, que más difícil que ser héroe es saber enfrentar con dignidad, sacrificio y entrega las muchas dificultades de todos los días". ${ }^{11}$

En 1955 Floria describió la posición de su generación a través de los hombres del '37. El lenguaje elusivo del pasado le servía para expresar su necesidad de pensar la realidad más allá de las antinomias del momento. Bajo el rosismo, que al igual que el peronismo había producido "una sociedad subvertida, desorientada, adormecida, moralmente vacilante y materialmente débil", surgió una generación desamparada que "se mantuvo por la fuerza equidistante de una política fragmentaria, improvisada que vivía al día, y de una oposición zigzagueante". El ejemplo de la generación del ' 37 era un programa de acción en sí mismo, basado en el desprecio al calor del poder y las seguridades; era un rechazo a las íntimas relaciones entre la jerarquía católica y el Estado de la última década, y al nacionalismo como una ideología que no dejaba resquicio para las dudas o el debate. La gene-

11 Floria, C. A.: "Nuestro triángulo", Criterio, 1319, 13 de diciembre de 1958, pág. 812. 
ración del '37, como la del '50, era una frontera con las adyacencias, que no se fundía con ninguna de ellas y "ése es el drama que arrastra consigo". El peronismo, a pesar de ser "una provocación antinatural, como es todo sistema que no respeta el valor original de la libertad humana", sirvió para que los católicos revalorizaran las instituciones democráticas. "La generación del 37 está sola" concluye Floria "su desamparo en medio de las fracciones en lucha no trajo desilusión, pero sí desconfianza". ${ }^{12}$

La experiencia del año '55 rompió los moldes de la inocencia que todavía quedaba entre los católicos. Los jóvenes del ' 50 se enajenaron del mundo de la política, y ese distanciamiento transformó su mirada. Estaban más convencidos de poder influir en la opinión pública y en la dirigencia católica, que en hermanarse en una ideología para participar en la lucha por el poder. Ese distanciamiento era producto de la mala relación con el mundo de los partidos y la intolerancia de los católicos hacia su actividad cotidiana. Su visión era demasiado unanimista como para comprender las fracturas y los reproches constantes entre dirigentes de casi todas las extracciones. El partido Demócrata Cristiano, que despertó sus expectativas, era escenario de las mismas disputas, los sectores que veían con simpatía su programa no desconocían las limitaciones de una agrupación tan imbricada ideológicamente. Según José Luis de Imaz, los miembros de su generación eran incapaces de convertirse en "hombres de partido", "Nos gustaba que nos llamaran, satisfacía nuestro 'ego' que prestaran correcta atención a nuestro curriculum. Pero lo que más nos placía era que nos 'cooptaran'. Desde el poder militar se nos liberaba de los costos de la lucha por el poder. Presentábamos el activo —nuestra impoluta vida profesional- y nos eximíamos del pasivo: la pelea cotidiana dentro de un partido político en el que no sólo no se respetarían nuestros títulos, sino que incluso se nos pospondría a causa de ellos". ${ }^{13}$

Los análisis sobre el mundo de la política partían de un componente moral fuerte y de un conocimiento técnico de la realidad argentina que se distinguía de los temas que los dirigentes trataban cotidianamente. Los intelectuales católicos se especializaron en áreas determinadas y desde esa perspectiva enjuiciaron la realidad política. En una década de racionalismo desarrollista, los enervaba la insensibilidad de los políticos hacia tópicos que consideraban esenciales, como el aprovechamiento de la Patagonia, la

12 Floria, C. A.: "Proyección histórica de una generación desamparada", Criterio, 1243, 8 de septiembre de 1955, págs. 649-650.

13 De Imaz, J. L.: Promediados los cuarenta, Sudamericana, Buenos Aires, 1977, pág. 249. 
cuestión social orientada a evitar un brote comunista o la profundización de la industrialización, a los que les dedicaban estudios, dossiers y números completos en revistas de inspiración católica.

Esta enajenación del mundo político y del poder tuvo también consecuencias en la relación entre los intelectuales católicos y la cúpula de la Iglesia. El grupo que más había confrontado al peronismo, muchos de cuyos miembros participaron en los comandos civiles de la Revolución Libertadora, se distanció de una jerarquía a la que consideraron timorata y acomodaticia. Por motivos similares, las tensiones dentro del seno del episcopado aceleraron la salida de Copello. ${ }^{14}$ La misma jerarquía se distanció del poder y se concentró en su propia crisis, y sólo excepcionalmente participó como intermediaria en conflictos sociales de magnitud.

Desde 1955 la jerarquía buscó recomponer la disciplina interna, haciendo llamados a la unidad de los católicos. La acompañaba el coro de los ex nacionalistas que no habían podido entrar en las formaciones políticas demócrata cristianas por su pasado oprobioso. Durante la organización del golpe de 1955, el PDC se había cuidado de mezclarse demasiado con los hombres de la vieja guardia, a pesar de que las circunstancias reclamaran un frente unido para oponerse al peronismo. ${ }^{15}$ El llamado a la unidad no tuvo mucha repercusión. Por más que la jerarquía convocara a los creyentes a ser fieles a su identidad, los fraccionamientos del mundo cultural y político del catolicismo eran lo suficientemente profundos como para

14 “...el hecho más macroscópico, el que mejor que ningún otro evidencia la laceración que la ruptura con el peronismo produjo en el tejido más íntimo de la institución eclesiástica, y que justamente por su carácter inusual fue motivo de insistentes rumores en los pasillos vaticanos: la decapitación de la cúpula eclesiástica argentina. La fracasada política de appeasement con Perón, que hasta el último instante defendió el cardenal Copello, en efecto, determinó su 'exilio' en Roma luego de haber perdido la autoridad necesaria incluso para ejercer el gobierno de su propia diócesis” en Di Stefano, R. y Zanatta, L.: Historia de la Iglesia Argentina: desde la conquista hasta fines del siglo XX, Grijalbo, Buenos Aires, 2000, págs. 469-470.

15 José Luis de Imaz ha señalado que la primera dirigencia de la Democracia Cristiana quería "hacerles purgar" a él y a otros jóvenes nacionalistas su pasado peronista. Ver: De Imaz, J. L: Promediados los... Mario Amadeo, por su parte, señaló que en una reunión previa al golpe de Estado de 1955 en la que estuvieron presentes Ayarragaray, Dell'Oro Maini, Oscar Puiggrós y otros dirigentes demócrata cristianos, le "manifestaron categóricamente que ellos venían trabajando en un movimiento que contaba ya con muchos años de elaboración, que ese movimiento tenía líneas definidas y una elevada tradición en el pensamiento y la política y que no era posible diluirlo en una estructura que abarcara núcleos de muy diferente origen doctrinario" "Mucho me temo" señalaba "que nuestros hermanos en la fe hayan aceptado sin muy riguroso beneficio de inventario las acusaciones que sectores de izquierda lanzaron contra los católicos de origen nacionalista con ánimo de dividirnos y que — acaso sin proponérselo - hayan hecho el juego al enemigo declarado de nuestros comunes ideales" en Amadeo, M.: Ayer, hoy, mañana, Gure, Buenos Aires, 1956, pág. 44. 
obviarlos. Roberto Bonamino, que había sido codirector de El Pueblo en sus años más nacionalistas, luego del derrocamiento de Perón pensaba que la unificación política de los católicos como ideal "tal vez requiera el sacrificio de hombres, pero, en cristiano no son los hombres los que deben prevalecer por encima de las conveniencias comunes". ${ }^{16}$ Los jóvenes maritanianos de la revista Comunidad rechazaron constantemente el convite. Desde su perspectiva, la división política de los cristianos no era un escándalo - como denunciaban muchos clérigos - porque la diversidad de posiciones no sacrificaba la unidad en Cristo. Juzgaban que el llamado a la unidad era "reaccionario" porque la función de un partido político católico era promover un conjunto de valores que inspiraran la instauración de una sociedad cristiana, y no defender los intereses de la Iglesia. ${ }^{17}$

La conflictividad en el seno del pensamiento católico en 1955 era similar a la que se producía en el resto de la intelectualidad argentina. Sin embargo, en el medio de los debates que se insinuaban, la llegada de un nuevo Papa al trono de Pedro en 1958 se convertiría en un vehículo de esperanza para los intelectuales católicos de la generación del ' 50.

\section{El Concilio Vaticano II en la Argentina}

Las divisiones dentro del campo de los intelectuales católicos revelan una profunda complejidad y evolución. Con ello, intentábamos poner en claro que la división entre "progresistas" y "reaccionarios", o, "concililiares", "posconciliares" y "preconciliares", a partir de los ejemplos, parece del todo inadecuada. En la misma línea, se vuelve infructuoso buscar un tema o móvil que nos permita identificar el motivo central de las disputas que se originaron en torno al Concilio Vaticano II. Romano y Tenenti han señalado que la reforma protestante "en parte interrumpió, en parte perturbó y en parte desvió" ${ }^{18}$ el amplio proceso del humanismo cristiano del siglo XVI. Podríamos decir que el Concilio Vaticano II hizo lo propio con el amplio debate teológico y eclesial que se inició a partir del fin de la Segunda Guerra Mundial. Específicamente, y dejando de lado toda preten-

16 Bonamino, J. R.: "Unidad política entre los cristianos. Izquierdismo, laicismo, materialismo”, Estudios, 471, noviembre-diciembre de 1955, págs. 18-19.

17 Ver Comunidad 1, 1956.

18 Romano, R. y Tenenti, A.: Los fundamentos del mundo moderno. Edad Media tardía, Renacimiento, Reforma, Siglo XXI, Madrid, 1972, pág. 228. 
sión totalizante, nos inclinamos a pensar que el Concilio representó en el campo de las ideas del catolicismo argentino una ampliación de la superficie discursiva, operando una crisis de legitimidad. ${ }^{19}$

Daniel Levine ha señalado que el Concilio Vaticano II hizo pública una discusión sobre dos modelos eclesiales: el primero, entendía a la Iglesia como una institución jerárquica, el segundo, la identificaba como una reunión del pueblo de Dios. Analizando el caso de las iglesias colombianas y venezolanas, Levine sostiene que el Concilio proveyó a la Iglesia nuevos modelos de relación con la sociedad, ligados a 1) un fuerte activismo social, 2) la toma de decisiones colegiada y 3 ) una creciente participación de los laicos en la vida de la Iglesia. Levine señala a su vez que, tanto en Colombia como en Venezuela, las organizaciones creadas para "reconquistar el mundo" al basarse en el modelo de la recristianización, irónicamente se convirtieron en "sospechosas" para la jerarquía, por la relación que entablaron con el mundo moderno y los discursos que arrastraron al seno de la Iglesia. ${ }^{20}$

Las afirmaciones de Levine nos permiten sostener que la crisis de la Cristiandad debe ser entendida como un proceso de pérdida de seguridades que otorgaba el esquema anterior al Concilio. Al ampliar el espacio de acción de los laicos, la pluralización de las estructuras eclesiales legitimaron la creación de una opinión pública al interior del catolicismo. La existencia de este espacio permitió que los discursos críticos y reformistas, especialmente aquellos que elaboraban los teólogos europeos, tuvieran un ámbito para su difusión y no pudieran ser simplemente eliminados. Gerard Defois sostiene que la crisis que abre el Concilio implica la pérdida del referente "normal" de la estructura simbólica del catolicismo. No significa sólo la mutación de valores y representaciones sino que al repensar la relación entre Iglesia y mundo, se abrió en el seno del catolicismo una tensión entre los valores "institucionalmente legítimos y los valores socialmente legítimos". ${ }^{21}$

19 La bibliografía sobre el Concilio es inabarcable, entre la más reciente puede consultarse Latourelle, R.: Vaticano II: balance y perspectivas: veinticinco años después (1962-1987), Sígueme, Salamanca, 1990. Alberigo, G.: Historia del Concilio Vaticano II, Sígueme, Salamanca, 1999; Touris, C.: "El catolicismo post-conciliar en Argentina. Ideas, prácticas y disputas en una Iglesia renovada" en Todo es Historia, 401, diciembre de 2000.

20 Levine, D.: "Authority in Church and Society: Latin American Models", Comparative Studies in Society and History, vol. 20, 4, octubre de 1978, págs. 517-544.

21 Dufois, G. : "Le pouvoir ecclésistique face aux cises et au changement" en AA. VV. : Le Pouvoir dans L'Église, Editions du CERF, Paris, 1973, pág. 51. 
El Concilio produjo una distensión en el plano de las obligaciones sociales generadas por la identidad religiosa. Esta afirmación puede verificarse en la pérdida del temor, por parte de los pensadores católicos, de expresar a viva voz sus diferencias, hacerlas públicas e incluso utilizarlas como parte de una estrategia autolegitimadora. Aunque las controversias dentro del catolicismo tenían una larga historia, lo novedoso en torno al Concilio fue que la diversidad como fenómeno ganó un lugar legítimo dentro del pensamiento católico. ${ }^{22}$

Pío XII, alarmado en 1950 por la difusión de ideas que en Roma se caratulaban como "neomodernistas", emitió la encíclica Humani Generis. Como sostenía un viejo contrincante de Maritain, el Papa intentó "hacer frente a esta peligrosa penetración del pensamiento específicamente moderno dentro de la filosofía y de la teología cristiana". ${ }^{23}$ La encíclica condenaba tres niveles de errores: 1) admitir "sin discreción ni prudencia el sistema evolucionístico", 2) el idealismo, el inmanentismo, el pragmatismo y el existencialismo y 3) el historicismo. Entre otras condenas, afirmaba que "Lo que algunos pretenden es disminuir lo más posible el significado de los dogmas; y librarlos de la manera de hablar tradicional [...] a fin de volver, en la exposición de la doctrina católica, a las expresiones empleadas por la Sagrada Escritura y por los Santos Padres [...] según ellos, los misterios de la fe nunca se pueden significar con conceptos completamente verdaderos, mas sólo con conceptos aproximativos y que continuamente cambian [...] De lo dicho es evidente que estos conatos, no sólo llevan al relativismo dogmático, sino ya de hecho lo contienen; pues el desprecio de la doctrina tradicional y de su terminología favorece ese relativismo y lo fomenta" ${ }^{24} \mathrm{La}$ encíclica condenaba en forma abierta los intentos de renovación y tenía como destinatario directo al jesuita y científico Pierre

22 Es interesante en este sentido la opinión de un intelectual católico como Jorge Mejía. En 1966 afirmaba que "La creación de una opinión pública en la Iglesia supone, en efecto, una operación delicada y vigorosa [...] Porque la opinión pública en la Iglesia o sencillamente no existe, o cuando existe tiene todavía características de brote lleno de promesas [...] Reconozcamos, sin embargo, que, según el estilo de los tiempos y con rasgos todavía indistintos, el 'público' en la Iglesia nunca ha dejado de expresar su opinión [...] En nuestro sentido, crear una opinión pública en la Iglesia es despertar la conciencia de la comunidad eclesial a la colaboración en una obra común [...] dejemos que se disienta de nuestra opinión, alegrémonos por ello, procuremos aprender de quien disiente. Y cuando nosotros disentimos, hagámoslo con la conciencia de que no por eso poseemos la llave de la ciencia ni con nosotros solos está casada la ortodoxia" en Mejía, J.:" Creación de opinión pública en la Iglesia”, Criterio, 1502, 23 de junio de 1966, págs. 446-450.

23 Meinvielle, Julio: La Iglesia y el mundo moderno, Theoria, Buenos Aires, 1966, pág. 246.

24 "Encíclica Humani Generis", Criterio, 1123, 14 de septiembre de 1950, pág. 601. 
Teilhard de Chardin; sin embargo, se vieron desautorizados todos aquellos que habían expresado su intención de transformar de una u otra manera las bases filosóficas en la que sustentaba el modelo de la cristiandad.

Pío XII emitió la encíclica Humani Generis en un intento de emular a Pío X, ${ }^{25}$ que mediante el decreto Lamentabili de 1907 había condenado, perseguido y aplastado a un conjunto de intelectuales católicos, sacerdotes y laicos, que encabezaron el denominado modernismo, ${ }^{26}$ acusándolos de ser "un compendio de todas las herejías". ${ }^{27}$ ¿Qué había cambiado en el mundo católico cincuenta años después? Con la vocación de recristianizar la sociedad, Roma exportó desde la década de 1920 un modelo de organizaciones católicas, solidificando un estamento dentro de la Iglesia que constituyó un público atento a las voces polémicas y cuestionadoras. Se formó una opinión pública - a veces más expuesta, a veces sólo detectable entrelíneas - que no estaba dispuesta a seguir viviendo en la ciudadela de la cristiandad, - un lugar cada vez más pequeño, frío y sin sentido —, rodeada por un mundo que se construía sin que el catolicismo pudiera hacer nada por cambiarlo.

Algunos impulsores del debate conciliar, como Mauriac, Leclercq y Guitton, eran viejos conocidos en el medio argentino. Otros rápidamente se convirtieron en las caras visibles de la renovación. El nombre del padre Yves Congar se transformó en el pan del día a partir de los años sesenta. Congar había protagonizado, junto al mítico grupo de Lyon en los años '30, el desarrollo de la nouvelle théologie. Su libro Los cristianos desunidos de 1937 fue considerado "peligroso" por Roma. Tuvo problemas para circular y fue prohibida su reimpresión. La escuela Le Saulchoir, en la que Congar participaba, se dispersó, y las reiteradas condenas de Pío XII a las innovaciones teológicas lo mantuvieron en un discreto y oscuro lugar. ${ }^{28}$ En la Argentina sus artículos se reproducían con asiduidad en Criterio, pero la nouvelle théologie era cuestionada desde la Revista de Teología de la Plata, dirigida por monseñor Raúl Ernesto Segura —uno de los representantes del episcopado argentino durante el Concilio- señalaba en 1954 que esta "novedad" engendrada alrededor de la revista $L a$ vie spirituelle exponía

25 Es interesante mencionar que entre 1951 y 1954 se procedió a la canonización de Pío X, una forma que tenía Pío XII de reafirmar la figura que había combatido al modernismo.

26 Ver Poulat, E.: La crisis modernista: historia, dogma y crítica, Taurus, Madrid, 1974.

27 Macquarrie, J.: El pensamiento religioso en el siglo XX, Herder, Barcelona, 1975, pág. 242.

28 Ver Jossua, J. P.: Yves Congar: un servidor doctrinal del pueblo de Dios, Guadalupe, Buenos Aires, 1966. 
una "desconfianza creciente hacia los medios externos, hacia los reglamentos, hacia las reuniones de misa, hacia la Acción Católica" ${ }^{29}$ Segura afirmaba que el menosprecio por lo institucional, por los medios "humanos", llevaba al menosprecio hacia la Iglesia y la jerarquía, es decir, llevaba directamente a la rebelión.

No todos los católicos argentinos tenían una visión tan crítica de Congar y del movimiento que éste representaba. En 1962, los profesores de la Facultad de Teología de la Universidad Católica de Buenos Aires, anticipando el clima conciliar, fundaron la revista Teología. Lejos de la influencia del siempre presente Octavio Nicolás Derisi, sus autores se abrieron a las nuevas corrientes, aun sin estar del todo convencidos de la radicalidad de los cambios propuestos. Congar, el más citado, les ofrecía a los pensadores católicos el equilibrio deseado entre unidad y diversidad; para una Iglesia que debía aceptar el cambio, la representación de la imagen de Dios también debía cambiar. "La relación religiosa" señalaba Congar "es verdaderamente una relación de alianza que se establece, primero, por la iniciativa gentil de Dios, pero también por la respuesta del hombre". Al proponer esta imagen consensual, las dos partes del acuerdo se volvían importantes. Dios representaba el principio de unidad; la Iglesia, el aspecto exterior de esa unidad. Comunión eclesial, creencia, cultos en la Iglesia representaban esa autoridad en forma externa pero, a su vez, la palabra era recibida por "alguien", que era el sujeto original de atribución, y encarnaba el principio de diversificación. Cualquier exageración de estos principios representa un peligro para el catolicismo: “...la búsqueda de la unidad por medio de la presión exterior es prima hermana del espíritu jurídico y del juridicismo. [...] La juridicidad acompaña fácilmente a la inclinación a preferir la acción exterior por presión a la acción interior por motivos personales. [...] El espíritu jurídico y la autoridad que le acompaña, no desean esto: es amigo de la seguridad, de lo que no reserve sorpresas, y desconfía de lo que busca, de los que no es forma definida y fija...". ${ }^{30}$

La atención a partir del Concilio se concentró en el problema de la relación entre el catolicismo y el otro, entendido como otro religioso, político o simplemente moderno. Este tópico se convirtió en el manto que cubrió todo el período conciliar y post—conciliar, con consecuencias y

29 Segura, E.: “¿Cristianismo de trascendencia o cristianismo de encarnación?”, Revista de Teología, 14, 1954, pág. 69.

30 Congar, Y.: "Diversidad y divisiones" en AA. VV.: Catolicismo uno y diverso, Estela, Barcelona, 1964, pág. 156. 
derivaciones múltiples. Abrirse o no al otro representaba, como mencionábamos en el apartado anterior, un punto clave en el clima de ideas de postguerra. Las transformaciones en torno a la relación con lo mundano implicaban para el catolicismo, en primer lugar, el fin del modelo de aislamiento y recristianización, que fue defendido hasta su último aliento por Pío XII. Quienes sostenían el modelo de la cristiandad pasaron a ser los "marginales" intelectuales en la Argentina, sostenidos casi exclusivamente por la jerarquía eclesiástica que se servía de cualquier discurso que anatematizara con cierta altura las ideas en boga en la Europa conciliar. Por otro lado, entre quienes creían efectivamente en la necesidad de dar por terminado el modelo de la cristiandad, no existía unanimidad de criterios acerca del límite que tendrían los cambios.

La liturgia se convirtió en otro motivo de controversias. Las transformaciones en las prácticas del culto habían sido impulsadas en la Argentina, entre otros, por escritores aglutinados en la misma Revista de Teología. El grupo de Rau apoyó fervorosamente el Concilio como defensores de la renovación litúrgica, basada en la participación más activa del laico en el ritual. Esto no implicaba que estuvieran de acuerdo con otras de las propuestas discutidas en Roma: Rau era un firme defensor del modelo de la cristiandad, especialmente en lo pertinente a las relaciones entre el Estado y la Iglesia. Por ejemplo, el grupo manifestó la inconveniencia de abusar de rótulos para intentar comprender las divisiones generadas entre laicos y cristinaos a partir del papado de Juan XXIII.

El debate sobre la liturgia no sólo giraba en torno al cambio de la lengua o al otorgamiento de una mayor participación de los laicos en la misa, lo que dividía las opiniones dentro del catolicismo eran las representaciones del modelo eclesial que se discutía a través de la liturgia. Por un lado, el mantenimiento del modelo vigente implicaba la reproducción del rito romano como modelo de universalidad; por el otro, el nuevo esquema adaptaba la liturgia a cada cultura particular, intentando una verdadera universalidad. De un lado, cada una de las Iglesias podría elaborar un ritual particular, ajustado a las diferencias temporales. Del otro, aquellas mentes acostumbradas a la uniformidad propia del modelo de la cristiandad veían en esta dispersión una transformación inaceptable.

El problema del rol de los laicos preocupaba también a los católicos argentinos. El Concilio le había otorgado un lugar especial al tema y se discutía su cambio de situación en el seno de la Iglesia. Este reconocimiento formaba parte del proceso que intentamos describir más arriba, la construc- 
ción de un conjunto de instituciones para recristianizar la sociedad a partir de los años '20 se volvía ahora una verdadera "opinión pública" que presionaba para otorgar mayor poder a los laicos en la estructura eclesiástica. En 1962, al iniciarse las sesiones en Roma, Criterio abrió sus páginas para que distintos representantes del catolicismo expresaran sus expectativas sobre el concilio. José Mirabella — que se definía como un "militante laico"- sostenía que "el concilio debe tratar de integrar a la Iglesia en el mundo moderno, bregar contra la tendencia a secesionarse, que es una nota fundamental de la época [...] Es principal que haga que los hombres de Iglesia y los católicos en general abandonen el espíritu de intransigencia, de autoritarismo, de autosuficiencia, ese orgullo consciente o inconsciente que lleva a ver en otros las causas de los males de la humanidad, sin darse cuenta de la proporción que nos cabe a nosotros en su origen [...] Se debe hacer del laicado, un conjunto de personas, que sienten, piensan y obran, no un rebaño sin voz al que se conduce ciegamente a su salvación....". ${ }^{31}$

Hemos distinguido el período abierto por el Concilio Vaticano II por la ampliación de la superficie discursiva del campo católico. De ahí la necesaria aparición de nuevas claves interpretativas, que inmediatamente se integraron a la competencia por la legitimidad, en un campo mucho más horizontal que el del período anterior. Sin embargo, no dejó de existir un centro jerárquico que emitiera discursos de una fuerza ineludible, independientemente de que estuviera autorizado o no, y aun cuando ese poder legitimador se había reducido - al mismo tiempo que otras fuentes de legitimidad se hicieron visibles - en tanto los católicos asumieron que estaban en "estado de concilio", es decir, habilitados formalmente a repensar y criticar, hacia adentro y hacia fuera, a la Iglesia y al mundo donde se insertaba. Enrique Dussel lo afirmaba sin tapujos en 1964 “... el Concilio Vaticano II ha autorizado a un cierto sector del catolicismo latinoamericano que antes debía guardar silencio. Este sector podrá ahora pensar teológica y pastoralmente el modo de vivir el cristianismo dentro de la civilización técnica universal que se instala lentamente en América Latina y que se le denomina a veces: el Mundo Moderno." ${ }_{32}$

Estas nuevas claves interpretativas se nutrían de elementos conocidos por el catolicismo argentino del programa del humanismo cristiano: la tolerancia, la revalorización del rol del laicado, la apertura de un espacio para la

31 "Encuesta de Criterio", Criterio 1416, 29 de noviembre de 1962 , pág. 862.

32 Dussel, E.: "Hacia una historia de la Iglesia latinoamericana", Stromata, vol. XXI, 1, 1964, pág. 501. 
participación y el debate, la puesta en duda de cuestiones que formaban parte de la tradición de la Iglesia. Las barreras dogmáticas que habían impedido su discusión, ahora eran historizadas, y por ende, desnaturalizadas.

Estas nuevas claves interpretativas, discursos que cuestionaban el statu quo, revelaban la importante discontinuidad que produjo el Concilio en la configuración del campo intelectual católico. Algunos autores han negado las dimensiones de esta transformación, muchos han reducido la discusión a un enfrentamiento entre integrismos de "izquierda" y de "derecha". ${ }^{33}$ Apoyados en las conexiones que el principal movimiento guerrillero argentino tuvo con el catolicismo integral nacionalista, se ha querido ver en este común origen la semilla de un mismo mesianismo. Esta operación implica obviar la riqueza y complejidad de los debates en cuestión ya que, desde esta óptica, sólo la matriz de la modernidad, entendida en términos del liberalismo, serviría para dividir a los "verdaderos" de los "falsos" renovadores, negando así la particular forma de apertura que los católicos que apoyaron el Concilio adoptaron en relación con "lo mundano". La ruptura del modelo de la Cristiandad permitió el acceso a nuevas claves interpretativas, que variaban desde una franca oposición al tomismo, hasta una adhesión más o menos crítica a la Teología de la Liberación.

33 Por ejemplo, J. M. Ghío sostiene que "In fact, the very modernity with which the Council was beginning to establish a relationship was made liable for the oppression suffered by the peoples at the periphery of capitalism. The situation, which in Argentina acquired a vertiginous tone as violence gradually displaced politics, suffocated the ecclesiastical renovation, and confronted it with a dichotomy between two forms of integralism: a classical one, right-wing and conservative, and another one, left-wing and revolutionary, equally subsumed under politics." en Ghío, J. M.: Catholic Church and Politics in Argentina (1880-1989), Ph.D., Dissertation at Columbia University, New York, 1995, pág. 299. Ver también "En Argentina faltó una Iglesia liberal" (reportaje), Todo es Historia, 286, pág. 71. David Rock ha señalado un tesis similar, basándose en el común rechazo del nacionalismo católico de derecha y los grupos posconciliares al liberalismo. Ver Rock, D.: La Argentina autoritaria: los nacionalistas, su historia y su influencia en la vida pública, Ariel, Buenos Aires, 1993. En la misma tesitura, Loris Zanatta ha señalado "No casualmente, muchas ideas profesadas por sacerdotes y laicos en los distintos organismos que dirigían — desde la JUC, la JEC, del MSTM, al MICAR entre otras— se hacían eco de las que habían animado, en los años treinta y cuarenta, la cruzada católica por el 'nuevo orden cristiano', si bien filtrado a través de la renovación conciliar y adaptadas al clima intelectual de los años sesenta y setenta, tan impregnados de utopías socialistas como el de treinta años antes lo había estado de utopías corporativistas" en Di Stefano, R. y Zanatta, L. Historia de la Iglesia..., págs. 525-526. De ninguna manera negamos el substrato fáctico de estas aseveraciones; consideramos, sin embargo, que se han formulado siguiendo una caracterización del catolicismo preocupada por verificar qué elementos tiene y qué elementos le faltan con relación al liberalismo político, más que por comprender al catolicismo en sus propios términos. Al mismo tiempo, se le ha dado mayor peso a ciertos sectores del catolicismo que cristalizaron en organizaciones más o menos próximas a los movimientos insurgentes, y se ha escapado el proceso de búsqueda, las críticas a la Cristiandad como modelo, y el pluralismo propio del período conciliar. 
La transición de un modelo cerrado y monolítico hacia una estructura de Iglesia abierta, como la denominaba Aranguren, implicaba la convivencia de claves interpretativas muy diversas, ${ }^{34}$ dentro de un proceso asentado en una inestabilidad estructural. La competencia de discursos y la apertura hacia la crítica producían en el campo católico el veloz envejecimiento de aquellas posturas que, promoviendo el cambio, se emitieron antes de 1962. De esta manera, Enrique Dussel en 1970 pensaba ya que Congar “... sigue con una conceptualización de cristiandad" que "no es realmente la que se necesita". ${ }^{35}$ Algo parecido se evidenció en la recepción que tuvo en los medios católicos argentinos el libro de Maritain, Le paysaine de la Garonne, donde en un tono autobiográfico demostraba sus temores y diferencias acerca del rumbo que había tomado la teología durante el Concilio. ${ }^{36}$ Las críticas revelaban las transformaciones vertiginosas de una dinámica que había adoptado el campo intelectual, en la cual "los maestros" duraban muy poco.

La crítica a la cristiandad se hizo consciente y explícita, los intelectuales católicos experimentaron la sensación de estar frente al fin de una época. En esa clave, Enrique Dussel dividía la historia de la Iglesia en tres etapas: la Iglesia primitiva, que promovía una gran libertad litúrgica y la existencia de pequeñas comunidades de base donde "El hombre conocía al

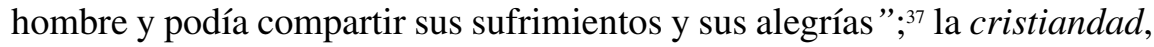
y el período posterior, que se iniciaba a partir de la convocatoria y desarrollo del Concilio Vaticano II. Tal periodización se combinaba con la reivindicación de la Iglesia original y primitiva, por su sencillez y sentido de la comunidad. Junto con el modelo de la cristiandad, entendido como un sistema de universalización de la tradición católica latina, debía ser eliminado el pensamiento europeizante que lo acompañaba. Dussel proponía entonces "pensar como argentinos", o mejor, como latinoamericanos..$^{38}$

Es indudable que el Concilio despertó la conciencia de los católicos sobre la realidad crítica que los circundaba. Narrar la historia de la Iglesia desde una perspectiva latinoamericana se convirtió en una opción indiscutible y en una señal que identificaba a los intelectuales cristianos del perí-

34 Ver Aranguren, José Luis: La crisis del catolicismo, Alianza, Madrid, 1969.

35 Dussel, E.: "Crisis de la Iglesia latinoamericana y situación del pensador cristiano en Argentina", Stromata, XXVIII, 3, 1971, pág. 330.

36 Ver crítica en Comunidad Nacional, 41, 1967, pág. 15.

37 Dussel: "Crisis de la Iglesia...", pág. 289.

38 Dussel: "Hacia una historia de la...", pág. 484. 
odo posconciliar. Justino O'Farrell reseñaba el proceso inexorable que llevaría a los argentinos a perder sus últimas aspiraciones de europeos. "Entre los rasgos principales del desenvolvimiento argentino es posible discernir los que preanuncian la rápida latinomericanización de lo que era la antigua Argentina Europea" ${ }^{39}$ A la identidad latinoamericana se amoldaba perfectamente la Teología de la Liberación que, en términos de Dussel, representaba un verdadero corte con el modelo de la cristiandad, el abandono de la noción de totalidad y del pensar en términos europeos..$^{40}$

El Concilio generó la apertura a corrientes que replantearon muchos de los principios que hasta ese momento habían sido considerados inamovibles en la Iglesia. Pero al mismo tiempo, obligó a salir a la palestra a quienes desde la muerte de Pío XII veían en los movimientos del tipo nouvelle théologie la penetración del mismísimo anticristo en el seno de la Iglesia. Entre ellos, Julio Meinvielle aparecía como uno de los intelectuales católicos que el clima democratizador de la postguerra no había logrado doblegar. Nacionalista y antisemita, representaba un núcleo de pensamiento que era apañado por la jerarquía eclesiástica, como lo demuestran las licencias concedidas a sus libros. La cúpula de la Iglesia tal vez no compartiera absolutamente todas sus ideas - tan políticamente incorrectas en 1965 - , pero a partir del Concilio, los unía la común sensación de estar asediados, sin poder respaldarse cómodamente en la autoridad romana. Como hacía treinta años lo había hecho con Maritain, a mediados de los '60, Meinvielle encaró la tarea de refutar a sus herederos intelectuales, los teólogos impulsores del Concilio: Congar, Schillebeekx, Chenu...

Meinvielle y sus contrincantes no discutían exactamente los mismos temas. Ellos se preguntaban cómo los católicos podrían seguir viviendo su cristianismo en el mundo moderno, lo que explicaba su optimismo, en tanto redescubrieron una sociedad mucho menos corrupta y laicista de lo que se presentía hasta ese momento. Para Meinvielle el problema giraba en torno a cómo organizar una sociedad basada en los principios católicos, colocando al poder al servicio de la función evangelizadora de la Iglesia. Allí el optimismo trocaba en pesimismo, y el hombre moderno se presenta como el símbolo del alejamiento de las enseñanzas de la Iglesia, en tanto ésta había perdido peso y funciones desde el surgimiento de la modernidad.

39 O’Farrell, J.: "La acción pastoral de la Iglesia en la Argentina. Su evolución”, Teología, 9, 1966, pág. 121.

40 Ver Beozzo, J. O.: Cristianismo e Iglesias en América Latina en vísperas del Vaticano II, Editorial DEI, San José, 1992. 
Meinvielle rechazaba la idea de que se estuviera produciendo un proceso hacia una "secularización de la Iglesia" convergente con una "eclesialización del mundo", como sostenían los "teólogos progresistas". "El "fuera de la Iglesia no hay salvación', por mucho que se explique en un sentido muy mitigado, como si la humanidad caminara 'invisiblemente' 'anónimamente', 'de incógnito' hacia la Iglesia, sólo podía hacerlo si caminase, al menos, hacia un Dios personal y providente; pero si, en su vida pública, esta humanidad no levanta otras realidades que lo Económico, o la Cultura, o el Sexo, o la Libertad, mal se podrá decir que camina hacia Dios cuando es impulsada por realidades puramente terrestres". ${ }^{41}$

El esquema mental de Meinvielle no dejaba escapar ningún concepto a las disputas entre categorías opuestas, binarias e irreconciliables: Dios o Satán, Iglesia o mundo, trascendente o histórico. Las relaciones entre el Estado y la Iglesia, como representantes de lo humano y lo divino, tampoco podían ser leídas fuera de una relación de subordinación. “...Congar omite", continuaba Meinvielle, "la valoración de un elemento capital, cual es la de fijar que 'la vida pública' del mundo o de la humanidad se ponga al servicio del fin de la Iglesia. Al no servir al fin de la Iglesia, esta "vida pública', que hoy se confunde con 'un poder público que actúa en todo el mundo y sobre todo el hombre', ha de actuar en la erección de la Ciudad de Satán". ${ }^{42}$

La última postura reseñada llevaba implícita la defensa del sistema en el cual la Iglesia se imponía al mundo, y sus leyes y las del Estado se confundían. Para Meinvielle, la cristiandad no era un período de la historia humana, sino un modelo de comportamiento a seguir por el poder y los hombres frente a la Verdad. "Al resistirse con tanta fuerza a la Cristiandad - a la que llaman odiosamente 'Teocracia' —, por la misma fuerza de las cosas, se someten a otra 'Teocracia', a la Teocracia de Satán...[...] El planteo de Congar, O. P., tal como aparece formulado, lleva implícito la negación del carácter mismo de toda existencia cristiana". ${ }^{43}$

En la entretela del discurso de Meinvielle se dejaba ver una imagen de Dios que se contraponía a las nuevas representaciones de la trascendencia. Como señaláramos al principio, la teología que precede y rodea al Concilio había construido una noción de Dios más consensual, una filosofía en la cual los hombres prestaban su aceptación a la palabra de Cristo. El Dios de

41 Meinvielle: La Iglesia y..., pág. 116.

42 Ibídem, pág. 107.

43 Ibídem, pág. 110. 
Meinvielle, en cambio, era el Dios autoritario de la cristiandad, al que los hombres debían temer y respetar, más que conocer y amar. "Es necesario señalar que Cristo, que salva" aclara Meinvielle, "también pierde. Es una piedra de tropiezo, de separación. [...] Cristo une, pero también separa. En Mateo dice Cristo "No penséis que he venido a poner la paz, sino espada". ${ }^{44}$

Meinvielle representaba la resistencia de un sector del catolicismo a la presencia de nuevas claves interpretativas en el campo intelectual católico. Pero no deberíamos ilusionarnos con la imagen absoluta y nítida de un personaje como "el padre Julio", la situación de los católicos frente a las innovaciones fue más sinuosa, menos rígida, más compleja y llena de matices.

En principio, los debates conciliares tuvieron distinta recepción en la Argentina. Algunas publicaciones católicas como la revista Estudios dedicaron poco espacio a la difusión de lo que sucedía en Roma. Otras, de carácter estrictamente teológico, se ocuparon con detenimiento de los documentos conciliares, pero sin reseñar la coyuntura. Sin duda, Jorge Mejía desde las "Crónicas conciliares" en la revista Criterio representó la percepción de los cambios conciliares "día a día" y su traducción al "hombre común". Sus crónicas han quedado algo olvidadas por la historiografía posconciliar, tal vez porque la revista Criterio fue identificada con una posición intermedia, afrancesada en oposición a lo latinoamericano, en una línea que la cultura política de fines de los '60 y setenta caracterizó como "intelectualista".

Jorge Mejía representaba las ideas del humanismo cristiano que, más allá de los matices que señalábamos más arriba, ganó presencia en el pensamiento católico a partir de la postguerra. Si el eje de ese programa giraba en torno a un diálogo posible y necesario que la Iglesia (y ya no grupos aislados de laicos) debía establecer con el mundo moderno, el carisma del "Papa Juan" parecía alimentar esas esperanzas. Desde las primeras "Crónicas conciliares", Mejía afirmaba: "Es seguro que el mundo espera algo del Concilio, aunque no sepa bien qué, ni cómo [...] debe tenerse muy en cuenta la adaptación al hombre y al pensamiento moderno, con gran paciencia, si es preciso". ${ }^{45}$ En octubre de 1964, en una larga argumentación, Mejía bregaba por la aprobación del "Esquema XIII" (luego la constitución Gaudium et Spes) que contenía la declaración sobre la libertad religiosa.

44 Ibídem, pág. 94.

45 Mejía, J.: "La inauguración del Concilio, hecho universal", Criterio, 1414, 25 de octubre de 1962, pág. 774. 
"El mundo no se está construyendo sin nosotros, sino contra nosotros; mucho tiempo hemos vivido en una ciudadela amurallada, corresponde ahora, no bajar los puentes, sino derribar los muros". ${ }^{46}$

En vísperas de la Navidad de 1965, cuando el Concilio llegaba a su fin, Mejía ensayaba el balance de una década. "La teología de los documentos conciliares es [...] la teología de la periferia. Los grandes artífices de esos documentos han sido hombres que, hasta hace poco, eran sospechosos en Roma". ${ }^{47}$ En la última sesión el documento sobre la libertad religiosa fue finalmente aprobado, ${ }^{48}$ Mejía se sentía satisfecho porque la obra del Concilio, el programa que el humanismo cristiano había impulsado desde el fin de la segunda guerra, ahora era dogma en la Iglesia. Como una última satisfacción, el afectuoso saludo que el Papa le dispensara a Jaques Maritain en la sesión de cierre del el 8 de diciembre aparecía como una postrera reivindicación. “ ...el Concilio, dice el Papa, no ha pronunciado anatemas, sino reconocido sus necesidades y valores, y procurado presentar un nuevo humanismo". ${ }^{49}$

El Concilio llegó a su fin en 1965 y el círculo se cerró sobre sí mismo. De la Humani Generis a la Gaudium et Spes, habían pasado quince años y tres Papas. El Concilio representó la explosión de un clima asfixiante, de una situación, para muchos, insostenible. Quedaba por delante la dura tarea de adaptación y puesta en práctica de las disposiciones conciliares. Sin duda, el Concilio vino a sancionar una línea que, en su propia lógica, abriría un conflicto que por muchas décadas laceraría el campo católico.

\section{A modo de balance}

Desde principios de los años cincuenta se afirmó en nuestro país una nueva generación de intelectuales portadora de una mirada crítica hacia el modelo de la cristiandad. Esa crítica no era homogénea: algunos asumían lo temporal mientras defendían la identidad católica como una necesidad.

46 Ibídem, pág. 816.

47 Mejía, J.: "Crónica Conciliar", Criterio, 1489/90, 24 de diciembre de 1965, pág. 957.

48 La bibliografía de análisis sobre las constituciones conciliares es inagotable. Pueden consultarse los números especiales de la revista Teología 7 y 8 dedicados a la Lumen Gentium y los números 10 y 11 a la Gaudium et Spes. Por otro lado, también son analizadas en el texto clásico de Laurentin, R.: Balance general del Concilio, Taurus, Madrid, 1967.

49 Mejía, J.: "Crónica...", pág. 958. 
Otros, más radicalizados, exigían que la ruptura se tradujera en un compromiso con la transformación de las estructuras económicas y sociales.

La nueva generación intentó pensar la realidad apartándose del espíritu de cruzada que había marcado a los intelectuales católicos de los años cuarenta. Querían llevar adelante (y no sólo declamarlo) una verdadera separación entre lo profano y lo sagrado, juzgando al mundo desde una óptica independiente; sin embargo, no deseaban dejar de ser católicos, ni creían que ambos niveles tuvieran la misma categoría, su discurso seguía emitiéndose desde una posición religiosa, pero integraba el aporte del otro. Así se sintieron hijos de una época que terminaba con diecisiete siglos de ostracismo mental.

Esta transformación en el pensamiento católico fue posible gracias a la modificación de la estructura de relaciones dentro del campo. En el interior de la Iglesia surgió una esfera crítica, un ámbito donde circularon estos nuevos discursos que, como hemos analizado, fue el resultado de un largo proceso nacido del impulso que la jerarquía brindó a la organización de entidades como la Acción Católica, basadas en el modelo de reconquista del mundo y aislamiento del creyente. Estos espacios se convirtieron en ámbitos de discusión, y permitieron que los católicos desarrollaran un proceso de autorreconocimiento. Así, la esfera crítica quedó en evidencia en los distintos eventos que jalonaron desde principios de los ' 50 el conflicto con el peronismo, y que en 1955 se hizo inocultable.

Creemos haber demostrado la discontinuidad entre el pensamiento de la generación de intelectuales integristas de los años '30 y '40 y la de los años cincuenta. Más allá de quienes sostienen que ninguna de las dos rompió con una concepción esencialista de la cultura, lo cierto es que la marca que distinguió a la generación del '50 es su distanciamiento del modelo de la cristiandad. Pero, ese proceso no fue lineal, ni homogéneo, ni estuvo libre de condicionamientos. Alejándonos de las disyuntivas temporales, como "avanzados" y "retrógrados", comprendimos la variedad de posiciones que se desplegaron en términos espaciales alrededor de un centro temático: la cristiandad como modelo. Su crisis modificó la lógica del campo, y debido al desarrollo de una conciencia crítica, la forma de autoridad tradicional perdió efectividad.

En cuanto a las relaciones entre los intelectuales católicos y la política, es cierto que aquellos sectores más adheridos a la cristiandad como modelo creían que sólo las Fuerzas Armadas podían garantizar los derechos de la Iglesia y los valores que representaba. Pero se trataba de grupos 
ideológicamente marginales, aunque tuvieran mejor acceso a la jerarquía y ésta se sintiera más a gusto con sus ideas. El humanismo cristiano se instaló, entonces, como el sentido común del campo, convirtiéndose en un tropo ideológico que todos reconocían. El conflicto universitario de 1958 fue un ejemplo de la nueva lógica discursiva, el reclamo de los católicos para tener sus propias universidades respondía al modelo de la cristiandad, pero utilizaron como argumento la libertad de enseñanza, y no la defensa de la "esencia católica" del pueblo argentino.

¿Es válido preguntarse, como otros han hecho en relación a la nueva izquierda, si estamos frente al fracaso de la generación del '50? De considerar válida la pregunta, la respuesta se presenta ambigua: por un lado, sus representantes eran portadores de un conjunto de ideas que sintonizaban con las que se discutían en la Europa de postguerra, aunque nunca elaboraron una ruptura formal con el pasado nacionalista, ni manifestaron sus ideas en forma programática. Si bien aspiraron a que el catolicismo se relacionara de un modo distinto con el Estado y la sociedad, con el objetivo de formular una religiosidad más austera y próxima al creyente, no pudieron rehuir la tentación de analizar en forma distante al poder, sin comprometerse demasiado con la suerte del sistema democrático. Más allá de sus posibilidades, los sectores más tradicionalistas siguieron gobernando la Iglesia argentina.

Dejaríamos un vacío historiográfico si obviáramos la existencia de quienes, desde perspectivas distintas, buscaron abrir el catolicismo al mundo en un aggiornamiento que empezó mucho antes que el Concilio le diera un estatuto formal. Instalaron y difundieron el discurso conciliar, y aspiraron a concretar una religiosidad más pura, más austera, más democrática y solidaria. El otro, ese enemigo desconocido que acechaba en las afueras de la cristiandad, se convirtió en alguien que, desde su alteridad, podía hacer de ellos mejores cristianos. 